\title{
Experimental Research on Liquid Desiccant Air-conditioning Unit
}

\author{
Yueyan Feng, Yinglin Li \\ Nanjing Normal University, School of Energy and Mechanical Engineering, 210042, China
}

\begin{abstract}
An experimental device of liquid desiccant air conditioning system is established. Experimental tests about the temperature difference between diluted solution of inlet and concentrated solution of exit in the solution heat exchanger are carried on, and $\mathrm{CaCl}_{2}$ solution is used as desiccant. Results show that: the fluctuation range in the day at different times of the basic difference of the measured temperature does not exceed $1{ }^{\circ} \mathrm{C}$, and the temperature difference between diluted solution of inlet and concentrated solution of exit in solution heat exchanger appears the minimum value of $2.7^{\circ} \mathrm{C}$ and the maximum value of $10.2^{\circ} \mathrm{C}$. Also, the percent of the additional load and the ratio of additional load to the evaporator load are analyzed.
\end{abstract}

\section{Introduction}

At present, the researches on the liquid desiccant system mainly concentrate in the padding, dehumidifiers, regenerators and other components, and few researches focus on the solution heat exchanger. Solution heat exchanger can recover thermal energy and increase thermal coefficient of unit [1]. On one hand, solution heat exchanger of the liquid desiccant unit increases the temperature of dilute solution and decreases the temperature of concentrated solution; on the other hand, after going through dehumidifier, concentrated solution becomes thin and cannot absorb moisture, so dilute solution needs to be concentrated and regenerated, the concentration of solution after going through heat exchanger is just to meet the requirements. Although the solution heat exchanger has above advantages, in terms of liquid desiccant system, there is a certain difference between the temperature of the concentrated solution and the dilute solution after going through solution heat exchanger. Thus this adds an additional consumption of the evaporator load.

In this paper the temperature difference between the diluted solution and concentrated solution in the solution heat exchanger is deeply explored based on experimental research, also the analysis about the additional consumption of load and the corresponding percentage of additional load is presented.

\section{The principle of liquid dehumidification air-conditioning system and test rig}

\subsection{The principle of liquid dehumidification air-conditioning system}

The temperature difference between the air and the solution is the driving force of heat transfer, the difference of the partial pressure of water vapor between in the air and in the surface of the solution is the driving force of mass transfer [2]. A liquid desiccant diagram is shown in Fig. 1. During the process of dehumidification, partial pressure of water vapor in the air is greater than partial pressure of water vapor in the surface of the solution, moisture in the air can be absorbed by the solution, and the moisture is passed to the solution, the air humidity decreases to achieve the purpose of dehumidification. During the absorbing process, the concentration of concentrated solution decreases and the capacity of moisture absorption gradually declines [3].

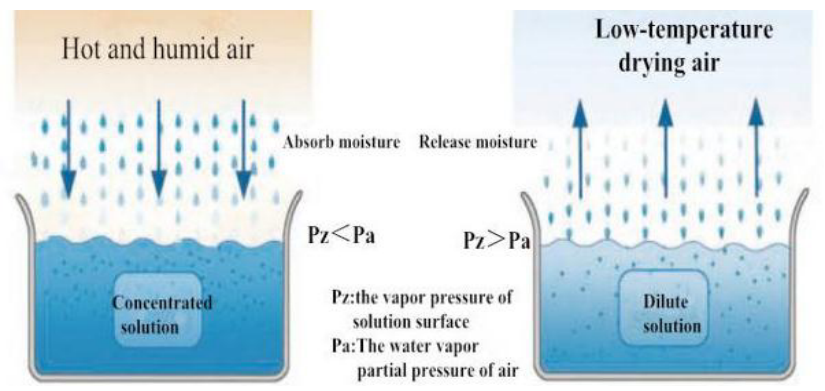

Figure 1. Schematic of liquid dehumidification principle

Regeneration process is the reverse process of dehumidification process, namely, the partial pressure of water vapor in the air is less than in the surface of the solution, so that the moisture transfers from the solution to the air.

The partial pressure of saturated water vapor in the surface of the solution increases with the increase of the solution temperature, the temperature of desiccant solution increases, and the water vapor pressure of the surface of the solution is greater than the partial pressure of the regenerative water vapor in the air, moisture 
transfers from the solution to the air, so that to achieve the purpose of the regeneration of the solution [4].

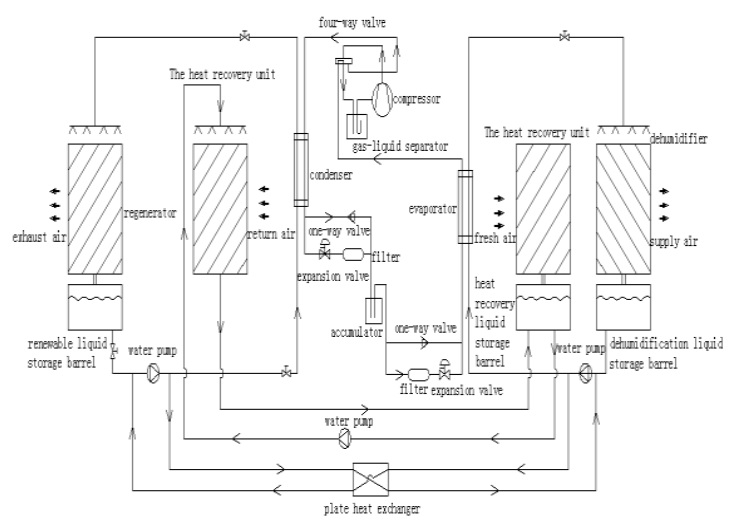

Figure 2. Diagram of heat pump heat recovery solution dehumidification unit

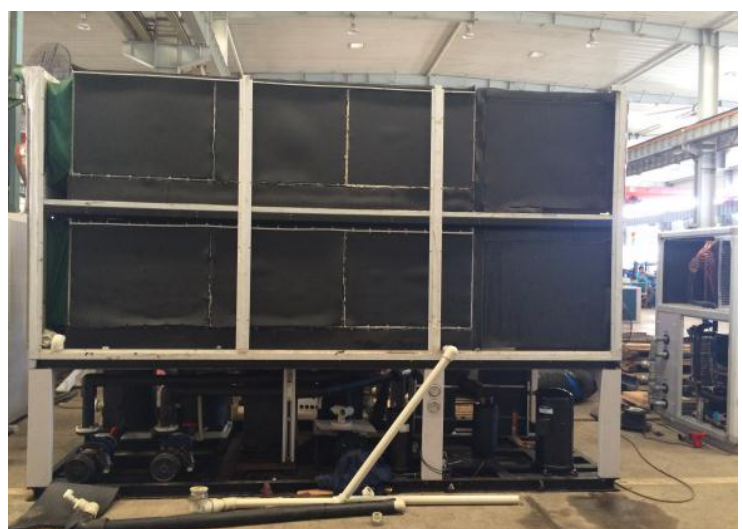

Figure 3. Test rig picture of pump type heat recovery solution dehumidification unit

Table 1. Main parameters of testing component in the test rig

\begin{tabular}{|c|c|}
\hline Component & Parameters \\
\hline Heat recovery module & Celdex, 980 $\mathrm{mm} \times 500 \mathrm{~mm} \times 300 \mathrm{~mm}$ \\
\hline Dehumidification module & Celdex, 980 $\mathrm{mm} \times 500 \mathrm{~mm} \times 300 \mathrm{~mm}$ \\
\hline Regeneration module & Celdex, $980 \mathrm{~mm} \times 500 \mathrm{~mm} \times 300 \mathrm{~mm}$ \\
\hline Solution tank & Plastic, diameter of $315 \mathrm{~mm}$, height of $450 \mathrm{~mm}$ \\
\hline Solution heat exchanger & Plate heat exchanger \\
\hline Water pump1 & $7.5 \mathrm{~m}^{3} / \mathrm{h}$, Lift of $12.5 \mathrm{~m}$ \\
\hline Water pump2 & $7.2 \mathrm{~m}^{3} / \mathrm{h}$, Lift of $14.6 \mathrm{~m}$ \\
\hline Water pump3 & $15.6 \mathrm{~m}^{3} / \mathrm{h}$, Lift of $4 \mathrm{~m}$ \\
\hline Fan in dehumidification side & Centrifugal fan RDK2.8A, 3000 $\mathrm{m}^{3} / \mathrm{h}$ \\
\hline Fan in regeneration side & DKNB $500-\mathrm{MOT} 90,2280 \mathrm{~m}^{3} / \mathrm{h}$ \\
\hline
\end{tabular}

\subsection{Test rig of heat pump heat recovery solution dehumidification unit}

Fig. 2 presents a heat pump heat recovery solution dehumidification unit; it mainly composes of the heat recovery module, dehumidification module, regeneration module, the solution heat exchanger, solution pump, solution tank, compressor, condenser, evaporator, expansion valves, the solution control valves, solution pipeline and other components. $\mathrm{CaCl}_{2}$ solution is chosen as the absorbent. Fig. 3 is the picture of the experimental rig. And the main parameters of relevant apparatus in the system are shown in Table 1 .

\section{Analysis of temperature difference of dilute solution and concentrated solution}

In the experiment, the plate heat exchanger is chosen as solution heat exchanger in the heat pump heat recovery solution dehumidification unit. The structure of plate heat exchanger is small size and light weight with the feature of higher heat transfer coefficient.

The calculation formula is given below for the specific heat capacity of Calcium chloride solution, enthalpy of solution, the percent of the additional load, the percent of the evaporator load and the ratio of additional load to the evaporator load .

1) The specific heat capacity of $\mathrm{CaCl}_{2}$ solution $C_{\text {Psol }}(T, \xi)[5]$

$$
\begin{gathered}
C_{P \text { sol }}(T, \xi)=C_{P H 2 O}(\theta) \times\left(1-f_{1}(\xi) \times f_{2}(\theta)\right) \\
C_{P H 2 O}(\theta)=A+B \theta^{0.02}+C \theta^{0.04}+D \theta^{0.06}+E \theta^{1.8}+F \theta^{8} \\
\theta=T / 228-1
\end{gathered}
$$

Type of each parameter are shown in Table 2

When $\varepsilon \leq 0.31$, then $f_{l}(\xi)=A \xi+B \xi^{2}+C \xi^{3}$

When $\varepsilon>0.31$, then $f_{l}(\xi)=D+E \xi$

$$
f_{2}(\theta)=F \theta^{0.02}+G \theta^{0.04}+H \theta^{0.06}
$$

$\varepsilon$ - concentration representation

Type of each parameter are shown in table 3

2) Enthalpy of solution $h_{L}$

$$
h_{L}=C_{P s o l}(T, \xi) \times t_{L}
$$

3) The percent of the additional load $\Delta h$

$$
\Delta h=C_{c, \text { out }} t_{c, \text { out }}-C_{d, \text { in }} t_{d, \text { in }}
$$

4) The percent of the evaporator load $q_{0}$

$$
q_{0}=C_{\text {in }} t_{l, \text { in }}-C_{\text {out }} t_{l, o u t}
$$

5) The ratio of additional load to the evaporator load $\varphi$

$$
\varphi=\Delta h / q_{0}
$$

Table 2. The value of various parameters from formula(1)to formula(3)

\begin{tabular}{|c|c|c|c|c|c|c|}
\hline & $\mathrm{A}$ & $\mathrm{B}$ & $\mathrm{C}$ & $\mathrm{D}$ & $\mathrm{E}$ & $\mathrm{F}$ \\
\hline $\mathrm{T} \leq 0^{\circ} \mathrm{C}$ & 830.54602 & -1247.52013 & -68.6035 & 491.2765 & -1.80692 & -137.51511 \\
\hline $\mathrm{T}>0^{\circ} \mathrm{C}$ & 88.7891 & -120.1958 & -16.9264 & 52.4654 & 0.10826 & 0.46988 \\
\hline
\end{tabular}

Table 3. The value of various parameters from formula(4)to formula (6)

\begin{tabular}{|c|c|c|c|c|c|c|c|}
\hline $\mathrm{A}$ & $\mathrm{B}$ & $\mathrm{C}$ & $\mathrm{D}$ & $\mathrm{E}$ & $\mathrm{F}$ & $\mathrm{G}$ & $\mathrm{H}$ \\
\hline 1.63799 & -1.69002 & 1.05124 & 0 & 0 & 58.5225 & -105.6343 & 47.7948 \\
\hline
\end{tabular}


Experimental data of inlet and outlet temperature of the heat exchanger is selected from seven time points: 2 : 30, 2: 45, 3:00, 3: 15, 3: 30, 3: 45, 4: 00 on April 20, April 25, April 30, May 5, May 10, which is plotted in Fig.4. Temperature experimental data is the average of data selected from seven periods: $1: 30-1: 55,2: 00-2: 25,2$ : 30-2: 55, 3: 00-3: 25, 3; 30-3: 55, 4: 00-4: 25, 4: 30-4: 55 on April 30, it is plotted in Fig. 5 .

The temperature difference in Fig. 4 and 5 represents the temperature difference between the concentrated solution in the exit and diluted solution in the inlet of solution heat exchanger.

As shown in Fig. 4, it can be seen that the value of temperature difference on April 20, April 25 and April 30 is almost in a straight line, the value of temperature difference on May 5 and May 10 fluctuates slightly, the line is gentle as a whole. The maximum value of temperature difference is $10.2{ }^{\circ} \mathrm{C}$ at $15: 30$ on May 5th, the minimum value of temperature difference is $2.7^{\circ} \mathrm{C}$ at 16:00 on April 20.

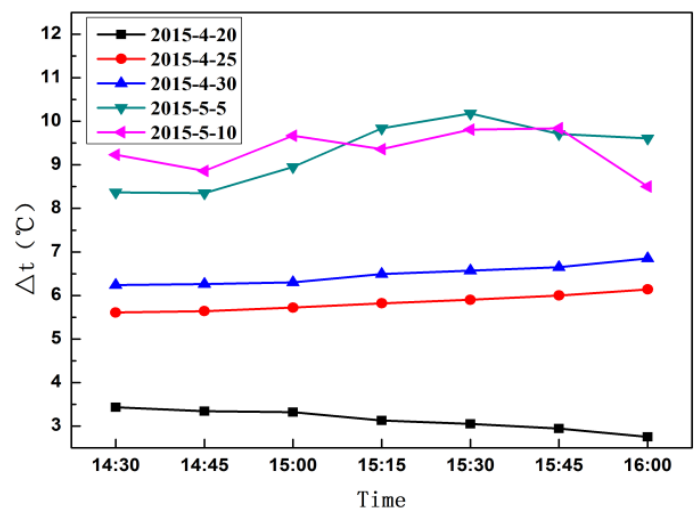

Figure 4. Temperature difference at different time points on five days

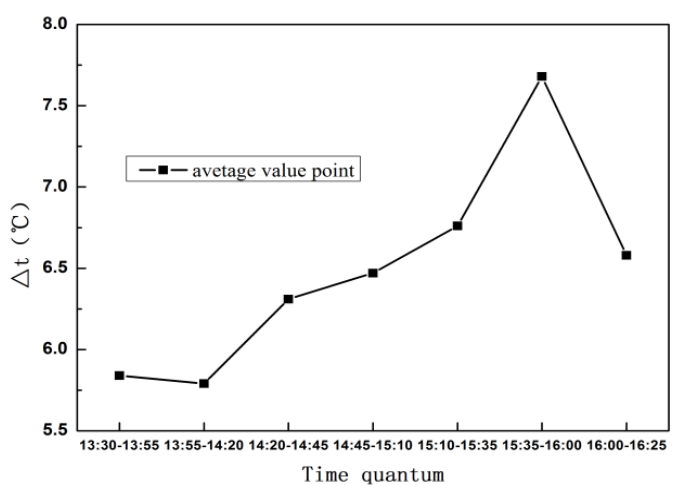

Figure 5. Temperature difference in different periods during one day

As can be seen from Fig. 5, the value of temperature difference fluctuates between $5.5{ }^{\circ} \mathrm{C}$ and $7.7{ }^{\circ} \mathrm{C}$ and has a peak in the period of 15: 30-16:00, the fluctuating range is about $2{ }^{\circ} \mathrm{C}$. Fig. 6 and Fig. 7 are corresponding percent of additional load of Fig. 4 and 5.

As presented in Fig. 6, the value of temperature difference on April 20, April 25 and April 30 is also in a straight line, the percent of additional load on May 5 and May 10 fluctuates slightly and the line is gentle on the whole. The minimum value of percent of additional load is $7.42 \mathrm{~kJ} / \mathrm{kg}$ at 16:00 on April 20 and the maximum value is $28.5 \mathrm{~kJ} / \mathrm{kg}$ at $15: 30$ on May 5 .

As can be seen from Fig. 7, the value of per unit mass of additional load on April 30 fluctuates between 15.8 $\mathrm{kJ} / \mathrm{kg}$ and $22 \mathrm{~kJ} / \mathrm{kg}$ and has a peak during the period of 15 : 30-16: 00, fluctuating value is about $6.2 \mathrm{~kJ} / \mathrm{kg}$.

Percentage of per unit mass of additional load accounts for evaporator load indicates the degree of influence that per unit mass of additional load has on evaporator load. Calculated percentage at different time points during five days and during one day are respectively plotted in Fig. 8 and 9.

According to Fig. 8, we can see percentage that per unit mass of additional load accounts for evaporator load on April 20 and April 30 presents almost a straight line and fluctuates slightly. The percentage has a valley value at 15:15 on April 25 and other values have less extent fluctuation. Fluctuating values on May 5 and May 10 are larger than other three days.

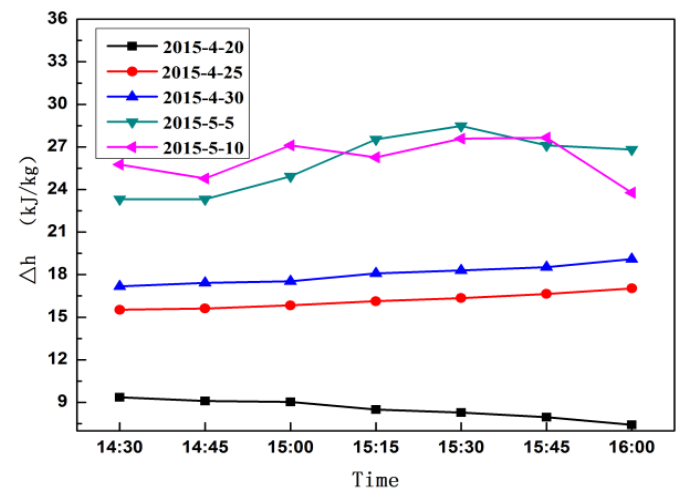

Figure 6. Percent of the additional load at different time points during five days

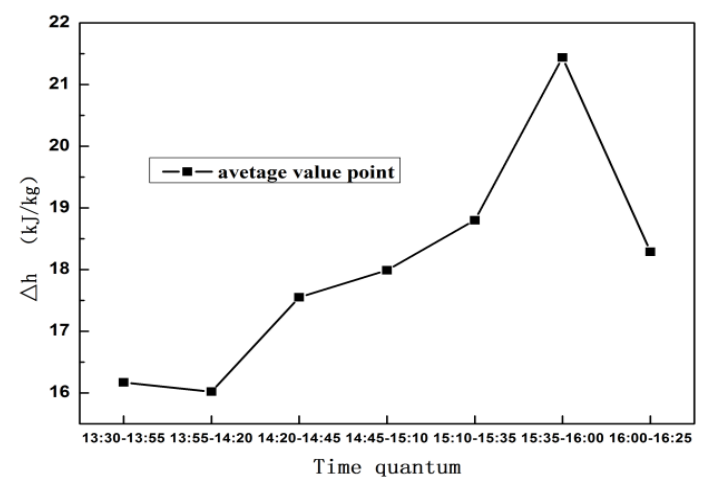

Figure 7. per unit mass of additional load diagram during different periods a day

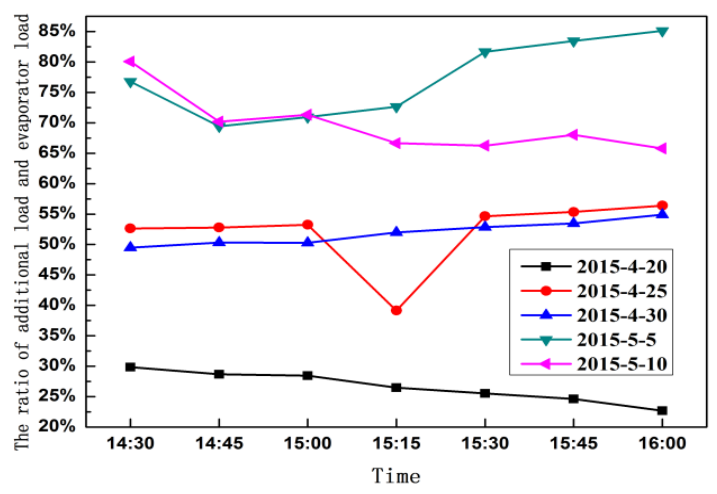

Figure 8. Rate of additional load to evaporator load at different time points in five days 


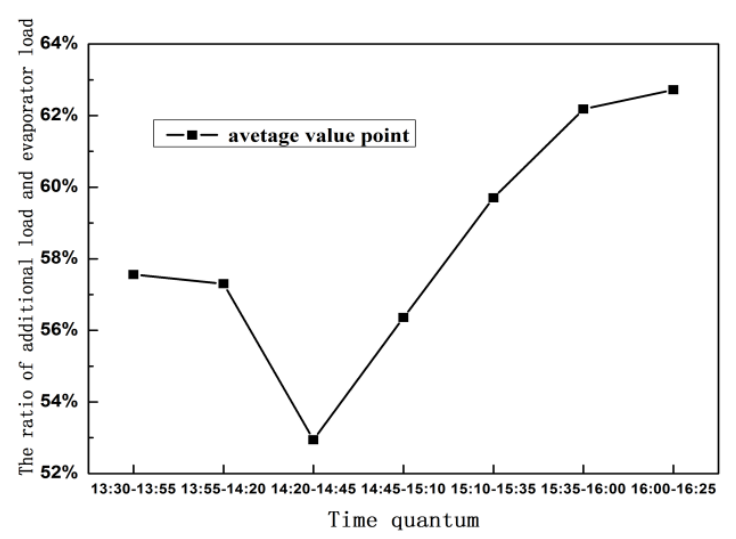

Figure 9. Rate of additional load to evaporator load at different time points

The variation trend of Fig. 5 and Fig. 7 is different; it has a valley value $52.9 \%$ during $14: 20-14$ : 45 . There is no rule from the whole variation.

\section{Conclusion}

1) The fluctuation range of temperature difference measured at different time a day is mainly within $1{ }^{\circ} \mathrm{C}$; Experimental data measured on different dates are different

2) On April 30, the value of temperature difference stabilizes between $5.5{ }^{\circ} \mathrm{C}$ and $7.7{ }^{\circ} \mathrm{C}$ and fluctuates about $2{ }^{\circ} \mathrm{C}$, the data may be affected by a particular value.

3 ) The temperature difference of concentrated solution on exit and dilute solution on entry of solution heat exchanger has the minimum value $2.75^{\circ} \mathrm{C}$ and the maximum value $10.18^{\circ} \mathrm{C}$, the minimum value and the maximum value of per unit mass of additional cooling load respectively are $7.42 \mathrm{~kJ} / \mathrm{kg}$ and $28.48 \mathrm{~kJ} / \mathrm{kg}$.

4) we calculate the percentage that additional load accounts for evaporator load and the number of the value indicates the degree of influence that dilute solution and concentrated solution has on evaporator after heat exchanging. The minimum value is $52.94 \%$ and the maximum value is $85.14 \%$, which has great impact on the evaporator but what kind of actions should be taken to decrease additional load need further study.

\section{References}

1. L. Jian, Study on heat transfer performance of solution heat exchanger about lithium bromide absorption refrigeration system, Refrigeration and Air Conditioning, 3, 68-70 (2006).

2. Z. W. Lian, Heat and mass transfer principle and equipment, China Building Industry Press, (2011).

3. SinoRefine Air Conditioning Technology Co., Ltd, Liquid desiccant type air handling units comprehensive manual[M] (Internal Information), First Edition, (2010).

4. J. W. Tang, Investigation of dehumidification process on falling-film of $\mathrm{LiCl}$ solution[D], Beijing University of Chemical Technology, (2007).

5. M. R. Conde-Petit, Aqueous solutions of lithium and calcium chlorides: Property formulations for use in air conditioning equipment design, M. CONDE ENGINEERING, (2009). 